Article

\title{
Enhanced Lifetime Cathode for Alkaline Electrolysis Using Standard Commercial Titanium Nitride Coatings
}

\author{
William J. F. Gannon, Daniel R. Jones and Charles W. Dunnill *(D) \\ Energy Safety Research Institute, Swansea University Bay Campus, Fabian way, Swansea SA1 8EN, UK; \\ 920920@Swansea.ac.uk (W.J.F.G.); d.r.jones@swansea.ac.uk (D.R.J.) \\ * Correspondence: c.dunnill@swansea.ac.uk; Tel.: +44-179-266-6230
}

Received: 10 January 2019; Accepted: 18 February 2019; Published: 21 February 2019

check for updates

\begin{abstract}
The use of hydrogen gas as a means of decoupling supply from demand is crucial for the transition to carbon-neutral energy sources and a greener, more distributed energy landscape. This work shows how simple commercially available titanium nitride coatings can be used to extend the lifetime of 316 grade stainless-steel electrodes for use as the cathode in an alkaline electrolysis cell. The material was subjected to accelerated ageing, with the specific aim of assessing the coating's suitability for use with intermittent renewable energy sources. Over 2000 cycles lasting 5.5 days, an electrolytic cell featuring the coating outperformed a control cell by $250 \mathrm{mV}$, and a reduction of overpotential at the cathode of $400 \mathrm{mV}$ was observed. This work also confirms that the coating is solely suitable for cathodic use and presents an analysis of the surface changes that occur if it is used anodically.
\end{abstract}

Keywords: titanium nitride; stainless steel; alkaline electrolysis; energy storage

\section{Introduction}

Developing high-performance electrode coatings for water splitting under room temperature, alkaline conditions remains of paramount importance as a means of storing excess renewable energy as hydrogen gas [1,2]. The use of hydrogen gas to decouple supply from demand is crucial for the transition to intermittent supplies of renewable energy and a greener energy landscape [3,4]. Alkaline electrolysis provides an alternative to Proton Exchange Membrane (PEM) electrolysis without the high costs, whilst retaining the high efficiency $[5,6]$. Storing energy cheaply and efficiently by conversion into hydrogen allows for a sustainable "Many-to-Many" energy landscape whereby multiple small-scale distributed energy inputs feed into the system, compared to the now outdated "One-to-Many" system whereby a single power station feeds to many houses and businesses. The "Many-to-Many" approach is far more resilient and sustainable given the intermittent nature of green energy inputs.

This paper examines the electrode stability and lifetime potential for stainless steel and a commercially coated titanium nitride electrode setup. The composition of stainless steels is governed by international standards and they are widely available, making them a cost-effective source of a reliable substrate material. Certainly, they are more widely available and cost-effective than a pure nickel substrate. The most common grades investigated for electrolysis are 304 (304SS) and 316 (316SS) [7-9], both of which are composed primarily of $\mathrm{Fe}, \mathrm{Ni}$ and $\mathrm{Cr}$, but with $316 \mathrm{SS}$ featuring a higher percentage of $\mathrm{Ni}$, in addition to about $2.5 \mathrm{wt} \%$ Mo. This affords $316 \mathrm{SS}$ greater resistance to corrosion, making it the first choice for marine and medical applications, but also making it more expensive, and potentially more difficult to obtain coating adherence. From the results reported by Carta et al. an overpotential for a $316 \mathrm{SS}$ cathode of $-0.34 \mathrm{~V}$ at $10 \mathrm{~mA} \mathrm{~cm}^{-2}$ was observed [8], but it has been clear to the authors over extended use that even $316 S S$ will experience significant cathodic corrosion (cf. Figure 7). 
Titanium nitride is known for its high thermal and electrical conductivity, in addition to its mechanical hardness [10], and is known to enhance electrode lifetime for the oxygen and hydrogen reduction reactions in a proton exchange membrane fuel cell [11]. However, to our knowledge it has not been investigated for use with intermittent alkaline electrolysis, so this work is the first study of its kind. In addition, it is widely available as a bespoke coating service for the lifetime enhancement of machine tools, alongside alternative coatings such as $\mathrm{CrN}$, TiAlN and $\mathrm{WS}_{2}$ [12]. In this context, the coatings are selected for their extreme hardness, and their ability to resist oxidation at the high temperatures generated during machining (which can exceed $800^{\circ} \mathrm{C}$ ). These properties are of secondary concern for room-temperature alkaline electrolysis, but the wide availability and accessibility of the coatings makes them potentially cost-effective. However, it remains to be seen which (if any) of these coatings constitutes the optimal trade-off between performance and cost. This study will focus on titanium nitride.

Accelerated Ageing

Electrode lifetime is often studied and reported within the scientific literature by employing constant currents, which are arguably of limited applicability in the field of intermittent renewable energy capture. Intermittent usage is recognised to play a significant role in the breakdown of electrocatalysts, especially ones involving nickel [13]. Therefore, to achieve rapid ageing, it was desired not only to subject the electrodes to large total quantities of current, but also to the destructive on-off cycling caused by the intermittent nature of renewable energy. A regime was devised that consisted of $2 \mathrm{~min}$ on, followed by $2 \mathrm{~min}$ under open-circuit conditions, permitting the electrodes enough time to both fully charge and discharge within each cycle, applying the corrosive stress on each change of phase. Room-temperature electrolysis is chosen because it is more applicable to renewable energy applications, where the demands of intermittency mean that permanent heating of the electrolyte is unsustainable.

\section{Materials and Methods}

\subsection{Electrodes}

The electrodes used were all 316-grade stainless steel $0.9 \mathrm{~mm}$ thickness cut to size and shape, either as supplied or coated in TiN using a standard commercial preparation delivering a 1 to $4 \mu \mathrm{m}$ thick TiN coating. The commercial titanium nitride coatings were applied by Wallwork Cambridge Ltd., UK, and their internal specification for the coating was "TIN COAT SPEC 300 1-4 MICRONS". In order to respect the intellectual property of the company, no attempts have been made to reverse-engineer the coatings, so it is not possible to report in this study how the coating thickness might affect performance. It is not expected that differences in coating thickness above $1 \mu \mathrm{m}$ will cause significant changes. This is because the material is electrically conductive, and because such a thickness constitutes many thousands of atoms, it is unlikely to affect the surface chemistry.

\subsection{Ageing}

All ageing experiments were conducted using a constant current power supply, connected to a two-electrode laminated electrolytic cell, which was primarily comprised of laser-cut acrylic plastic (see Figure 1) [14]. A Zirfon ${ }^{\mathrm{TM}}$ membrane was used to keep the evolved gases separate, and the distance between electrodes was approximately $30 \mathrm{~mm}$ [5]. Two different ageing protocols were followed, as detailed in Table 1. It was observed that at the higher current density a stronger electrolyte was needed to keep the total voltage drop across the electrolytic cell, and with it the associated ohmic heating, within reasonable limits. The choice to use $\mathrm{NaOH}$ instead of the more usual $\mathrm{KOH}$ was made because it is cheaper, and therefore more practical for commercial applications. Also, even though the safety data sheet states that it must never be disposed of down the drain, it is widely recognized and 
used as a drain cleaner, and therefore accidental spillage or leakage into the sewer is a manageable environmental hazard.

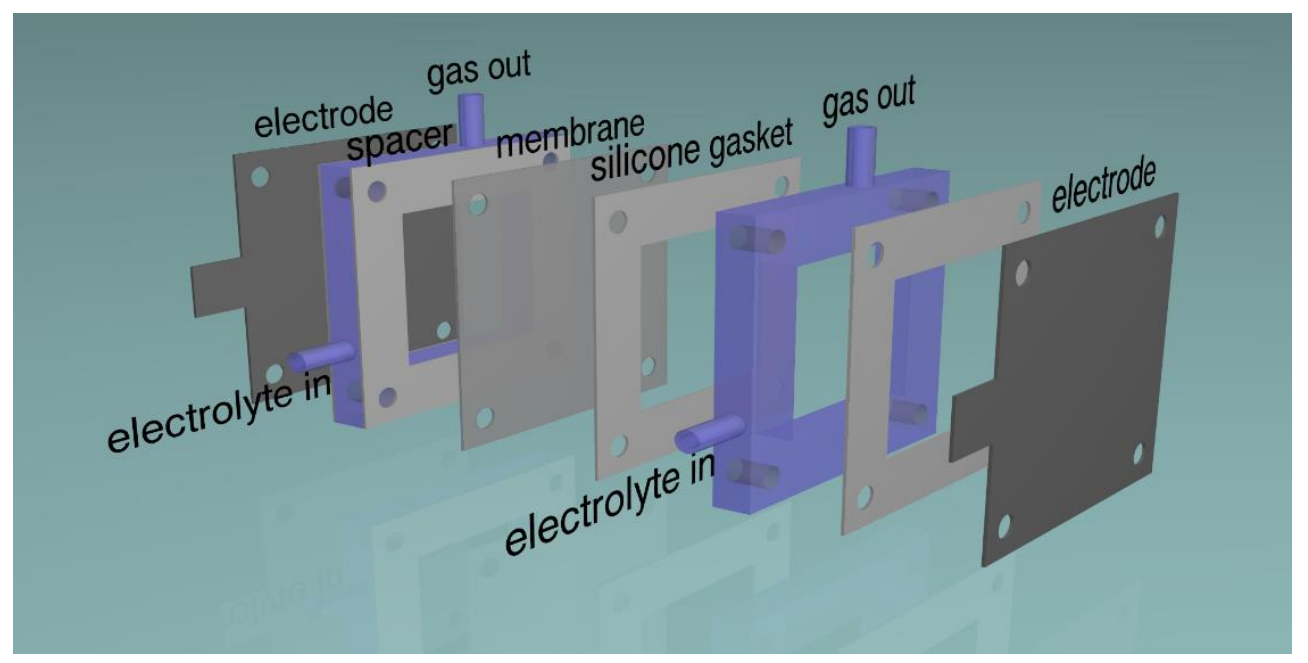

Figure 1. Typical design of experimental electrolytic cell, based on laser-cut components.

Table 1. Different accelerated ageing protocols employed.

\begin{tabular}{cccc}
\hline Ageing Protocol & Current $\left(\mathbf{m A ~ c m}^{-\mathbf{2}}\right)$ & Cycles & Electrolyte \\
\hline A & 100 & 2000 to 2500 & $0.5 \mathrm{M} \mathrm{NaOH}$ \\
B & 200 & 2000 to 2500 & $1 \mathrm{M} \mathrm{NaOH}$ \\
\hline
\end{tabular}

Each experiment lasted between 5.5 and seven days. made up of 4-min cycles. In some experiments the electrolyte was circulated through a single external chamber using a small brushless pump.

\subsection{Three Electrode Experiments}

All three-electrode experiments were conducted on an Ivium (Eindhoven, The Netherlands) n-Stat potentiostat, connected to a similar design of electrolytic cell. The working electrode (WE) surface area was reduced to $9 \mathrm{~cm}^{2}$ by gluing or bolting the electrode to a laser cut sheet of $3 \mathrm{~mm}$ clear acrylic containing a $3 \times 3 \mathrm{~cm}$ window. The counter electrode was a 316 stainless-steel plate (of which $6 \times 6 \mathrm{~cm}$ was exposed), and the reference electrode (RE) was a commercial design involving a $\mathrm{Ag} / \mathrm{AgCl}$ wire suspended in $3 \mathrm{M} \mathrm{KCl}$. The distance between working and counter electrodes was approximately $15 \mathrm{~mm}$. The electrolyte was $0.5 \mathrm{M} \mathrm{NaOH}$ (standard reagent grade) and deionised water was used throughout. Before each experiment the RE was checked against a standard calomel electrode (SCE), and the electrolyte was bubbled with nitrogen for $10 \mathrm{~min}$ to reduce dissolved oxygen. All experiments were conducted at laboratory ambient temperature, which was $20 \pm 1^{\circ} \mathrm{C}$.

\subsection{Tafel Slope}

The procedure outlined by Stevens et al. was followed to obtain measurements of the Tafel slope [15]. This involved chronopotentiometry steps at varying current densities and durations as specified in Table 2.

Each experimental run consisted of both ascending and descending Tafel slopes, with the whole procedure repeated twice. The published results are taken from the descending slope of the second run. 
Table 2. Current densities and durations for Tafel analysis.

\begin{tabular}{ccc}
\hline Step & Current Density $\left(\mathbf{A ~ c m}^{-\mathbf{2}}\right)$ & Duration (Seconds) \\
\hline 1,14 & $1.0 \times 10^{-5}$ & 480 \\
2,13 & $3.2 \times 10^{-5}$ & 480 \\
3,11 & $1.0 \times 10^{-4}$ & 240 \\
4,10 & $3.2 \times 10^{-4}$ & 120 \\
5,9 & $1.0 \times 10^{-3}$ & 120 \\
6,8 & $3.2 \times 10^{-3}$ & 120 \\
7 & $1.0 \times 10^{-2}$ & 120 \\
\hline
\end{tabular}

\section{5. iR Correction}

In order to correct for voltage losses in the electrolyte between the reference and working electrodes, electro impedance spectroscopy (EIS) was performed between $100 \mathrm{~Hz}$ and $1 \mathrm{MHz}$. The series resistance of the electrolyte was then defined as the magnitude of the point of closest approach to the origin of the resulting Nyquist plot. The voltage drop across the electrolyte could then be cancelled out simply by multiplying this resistance by the total cell current.

\subsection{Electron Microscope}

Scanning electron microscope (SEM) imaging and energy-dispersive spectroscopy (EDX) were performed on an Oxford Instruments (Oxford, UK) AZtecOne spectrometer attached to a Hitachi (Tokyo, Japan) TM3030 table top microscope.

\section{Results and Discussion}

Cyclic voltammetry experiments revealed that the TiN coating cannot be employed as an anode, even for brief periods, which is in agreement with previous findings $[16,17]$. The positive electric potential caused the coating to change rapidly from the original gold colour to orange-brown in just a few tens of seconds, accompanied by the loss of the great majority of the electrical conductivity. The physical origin of this change was investigated using XPS, as described in Section 3.2. Any TiN-coated electrodes present in a commercial electrolyser would therefore be at significant risk of destruction should the incorrect polarity mistakenly be applied.

The electrical performance comparison of both the stainless-steel and TiN-coated cathodes is as shown in Figure 2. These results show that the Tafel slopes for both materials are very nearly the same. Both are largely parallel to the $120 \mathrm{mV} /$ decade value (shown as a dashed line), which is the value anticipated from theoretical calculations within the literature [18]. However, the coated electrode requires approximately an extra $300 \mathrm{mV}$ of overpotential to achieve the same current density as the uncoated material.

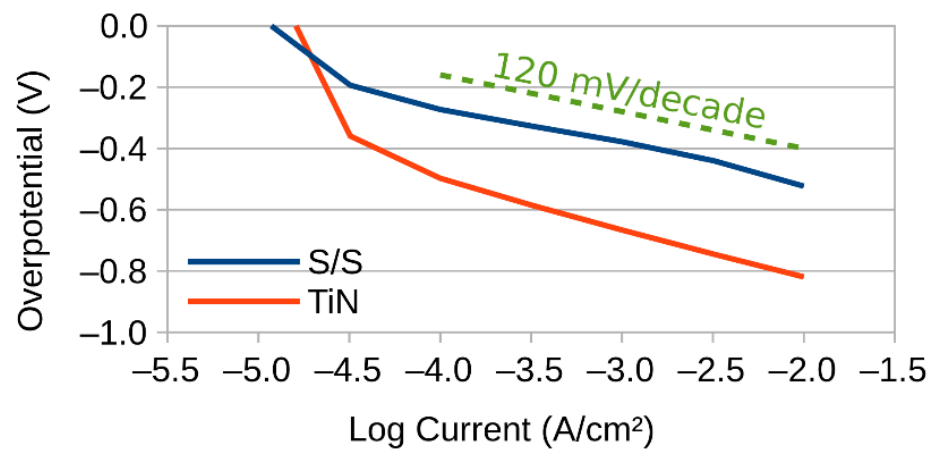

Figure 2. Tafel plots for stainless-steel and TiN before ageing. 
Figure 3 shows the visual representation of the electrodes after Ageing Protocol A. Here it can be seen that the TiN-coated cathode (Figure 3e) retained much of its original golden colour, as opposed to the uncoated stainless steel (Figure 3c), which became almost purple.

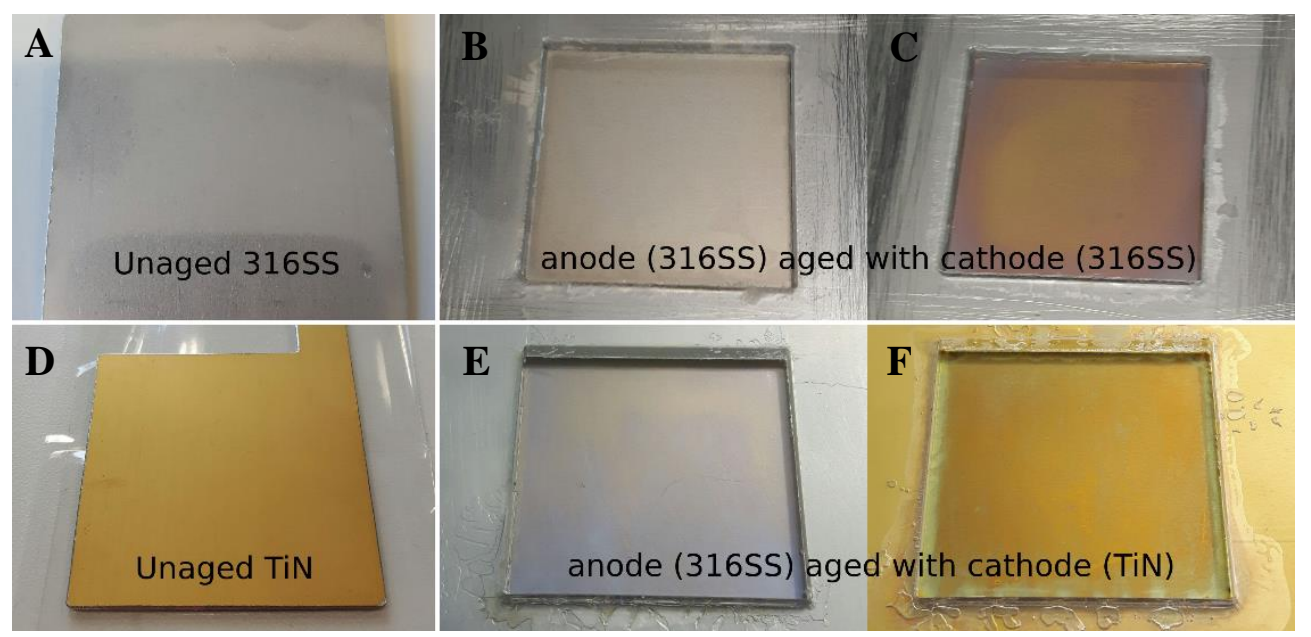

Figure 3. Visual appearance before and after Ageing Protocol A of 316 stainless-steel electrodes both coated in TiN and uncoated. (A) is original unaged electrode, $(\mathbf{B})$ and $(\mathbf{C})$ are the anode and cathode respectively), (D) is the unaged TiN coated electrode, (E) and (F) are the anode and cathode respectively.

During these experiments, neither combination exhibited much variation in two-electrode electrical performance, as shown in Figure 4. This indicates that both materials are electrically stable long term, at least at this current density. Note also that the TiN cell consistently required approximately an extra $250 \mathrm{mV}$, which agrees well with the three-electrode results presented in Figure 2. We may therefore conclude that most of this additional voltage is a result of the TiN coating on the cathode.

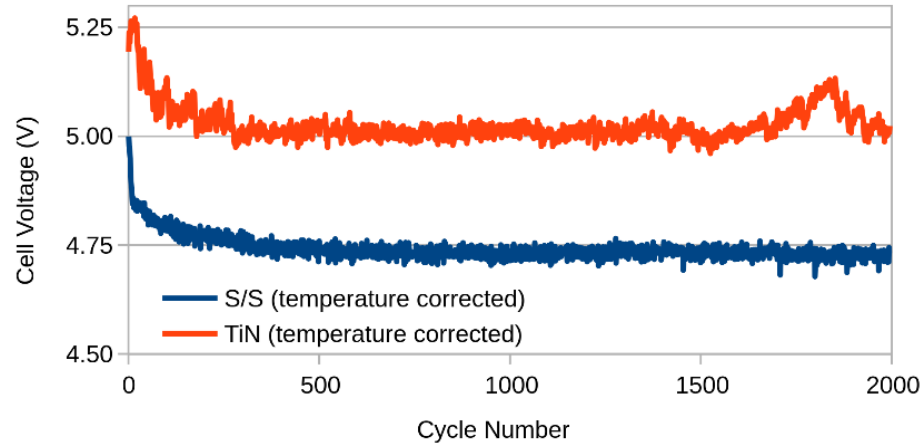

Figure 4. Variation of cell voltage over 2000 cycles of Ageing Protocol A.

Further long-term tests were conducted at $200 \mathrm{~mA} \mathrm{~cm}^{-2}$ to test whether the electrical performance of the uncoated stainless-steel cathode would degenerate if subjected to greater accelerated ageing, as shown in Figure 5.

Here it can be seen that the voltage was lower in general, due to the higher concentration of the electrolyte. Also, the initial $300 \mathrm{mV}$ difference was quickly overturned, and thereafter the gap gradually extended until finally the TiN cell outperformed the stainless-steel cell by about $250 \mathrm{mV}$. This performance improvement is not necessarily attributable to the cathode, since it is a two-electrode cell, and therefore does not permit an individual assessment to be made of either electrode. To assess this, three-electrode experiments were again performed to measure the electrical performance of the cathodes in isolation, as shown in Figure 6. 


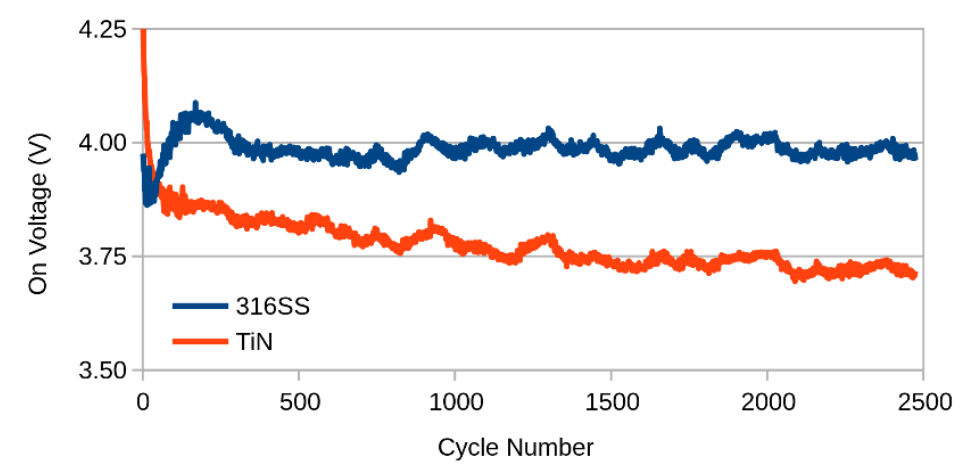

Figure 5. Variation of cell voltage over 2000 cycles of Ageing Protocol B.

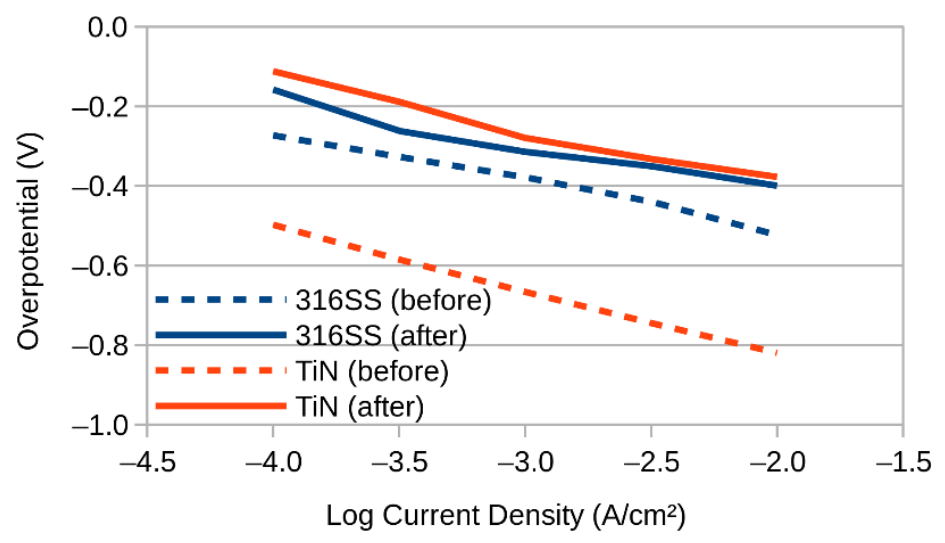

Figure 6. Tafel plots before and after Ageing Protocol B.

The TiN cathode was now able to outperform the stainless cathode, although only by about $20 \mathrm{mV}$. The improvement seen in Figure 5. is therefore likely due to factors other than the cathode alone, such as the electrolyte, membrane or anode. Perhaps of greatest significance is the observation that the anode used in conjunction with the TiN cathode had taken on a coppery appearance, and it is possible that this has led to an unexpected and unexplained increase in performance. Also significant is that both cathodes improved over the course of the experiment, with the TiN cathode overpotential decreasing by a remarkable $400 \mathrm{mV}$.

Despite this improvement in electrical performance, both electrodes exhibited significant deterioration in their visual appearance, as shown in Figure 7. Nevertheless, it is perhaps indicative of their potential for real-world longevity that their appearance improved after immersion for three days in fresh $0.5 \mathrm{M} \mathrm{NaOH}$ (see right-hand images of Figure 7), despite being almost completely black immediately after accelerated ageing. 

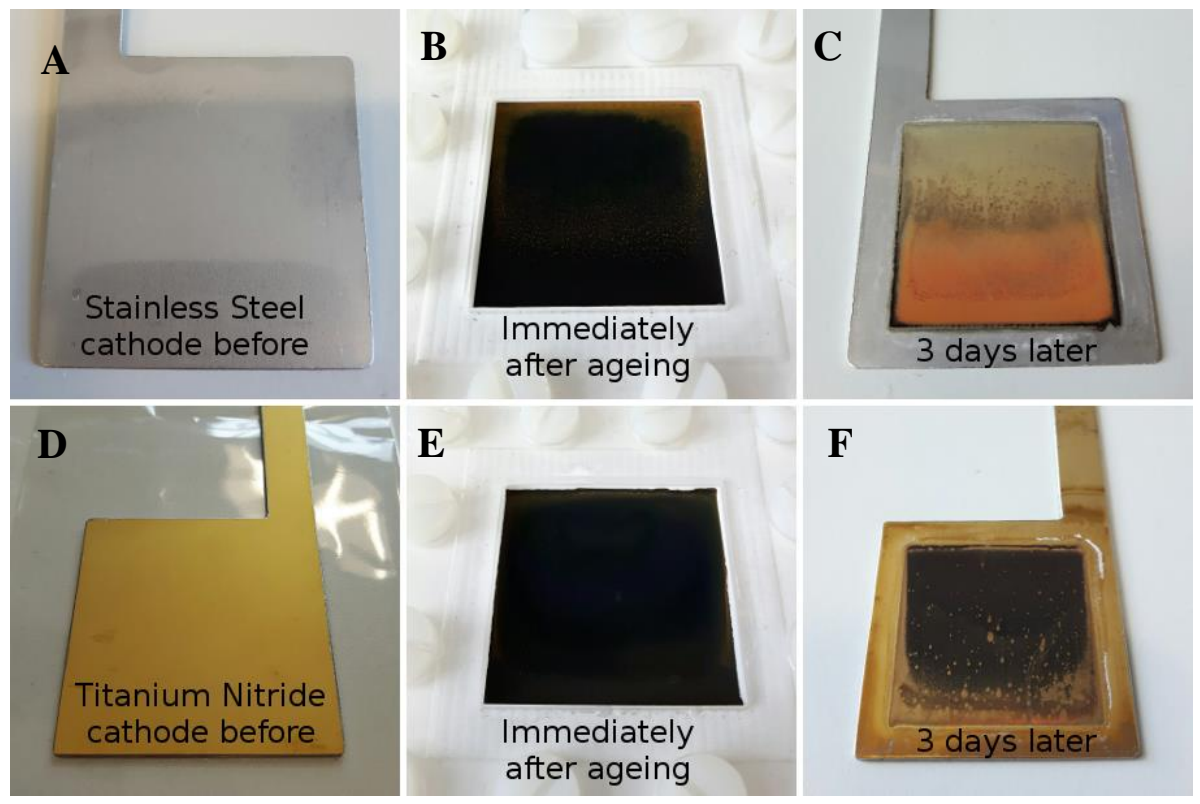

Figure 7. Visual appearance before and after Ageing Protocol A of 316 stainless-steel cathodes both coated in TiN and uncoated. (A) is original unaged cathode, $(\mathbf{B})$ is immediately after aging, $(\mathbf{C})$ is after a further 3 days sitting in $0.5 \mathrm{M} \mathrm{NaOH}$, (D) is original unaged TiN coated cathode, (E) is immediately after aging, (F) is after a further 3 days sitting in $0.5 \mathrm{M} \mathrm{NaOH}$.

\subsection{SEM and EDX}

The cathodes from Figure 7. were analysed using SEM and EDX, since their smaller design permitted them to be mounted inside the electron microscope, with the results as presented in Figure 8 and Table 3. The SEM micrograph showed the presence of crystals, and it was apparent from the EDX spectrum obtained that they were comprised primarily of copper. This could be attributed to the layer of copper applied underneath the TiN during the commercial titanium nitride deposition.

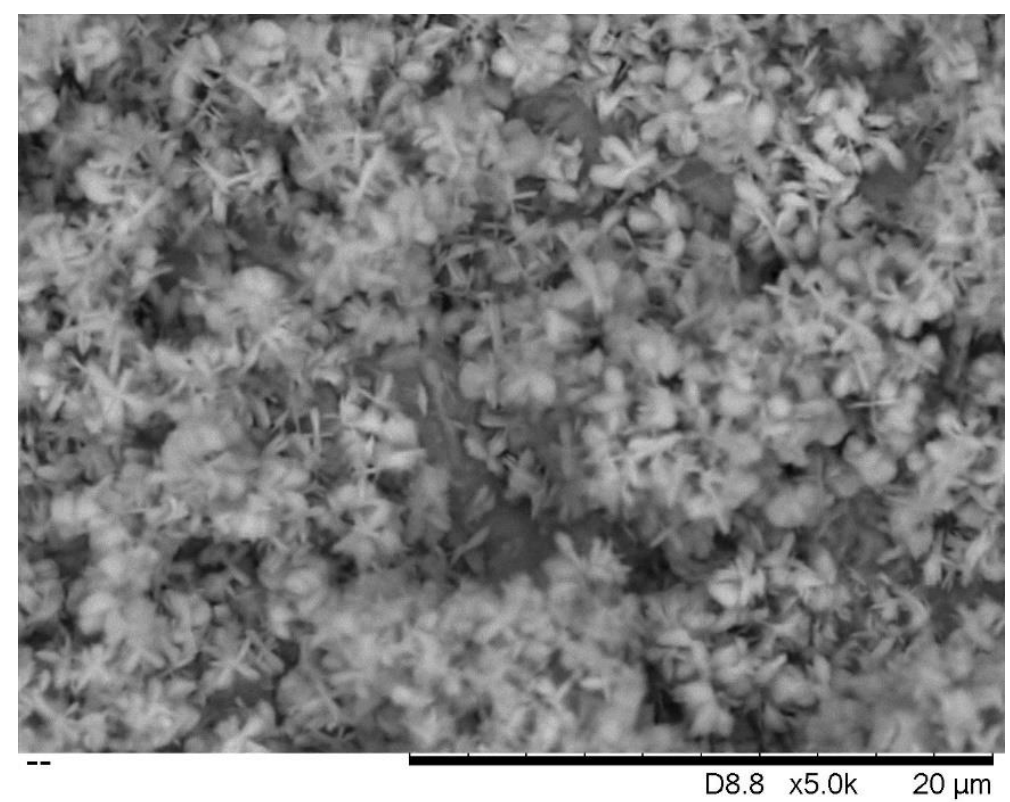

(A)

Figure 8. Cont. 


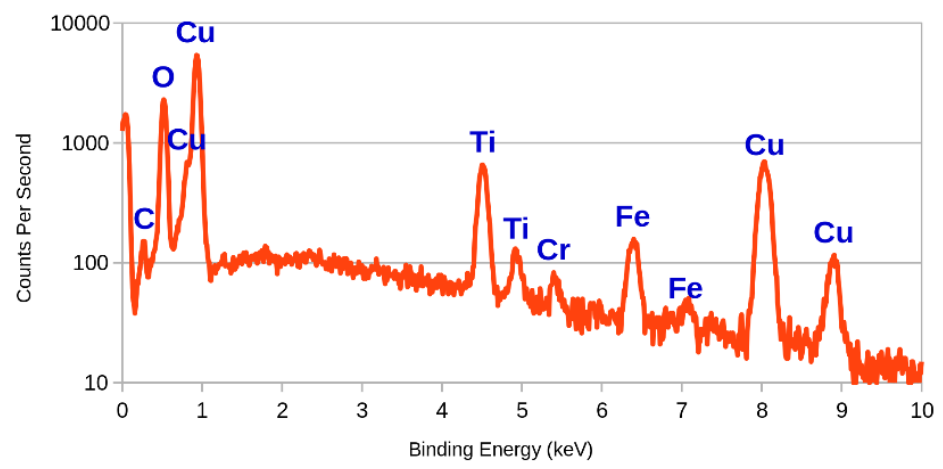

(B)

Figure 8. Electron micrograph at 5000x magnification (A) and EDX spectrum of the crystalline deposit (B) for the titanium nitride cathode after Ageing Protocol B.

Table 3. Quantitative analysis of the above EDX spectrum for the crystalline deposit.

\begin{tabular}{ccccc}
\hline Element & Line Type & Weight $\%$ & Sigma & Atomic $\%$ \\
\hline $\mathrm{Cu}$ & L series & 61.00 & 0.58 & 31.84 \\
$\mathrm{O}$ & K series & 24.07 & 0.38 & 49.90 \\
$\mathrm{Ti}$ & K series & 6.86 & 0.15 & 4.75 \\
$\mathrm{Fe}$ & K series & 3.30 & 0.16 & 1.96 \\
$\mathrm{C}$ & K series & 3.28 & 0.36 & 9.05 \\
$\mathrm{~N}$ & K series & 0.90 & 0.64 & 2.13 \\
$\mathrm{Cr}$ & K series & 0.60 & 0.09 & 0.38 \\
& \multicolumn{2}{c}{ Total } & & $\mathbf{1 0 0 . 0 1}$ \\
\hline
\end{tabular}

For the stainless-steel cathode, the appearance was as shown in Figure 9. There was a marked difference between the top half of the electrode (location ' $a$ '), which appeared unaffected, and the bottom half (location ' $b$ '), which was covered in small particles approximately $500 \mathrm{~nm}$ across. EDX analysis of the particles confirmed that they were $70 \%$ copper by weight.
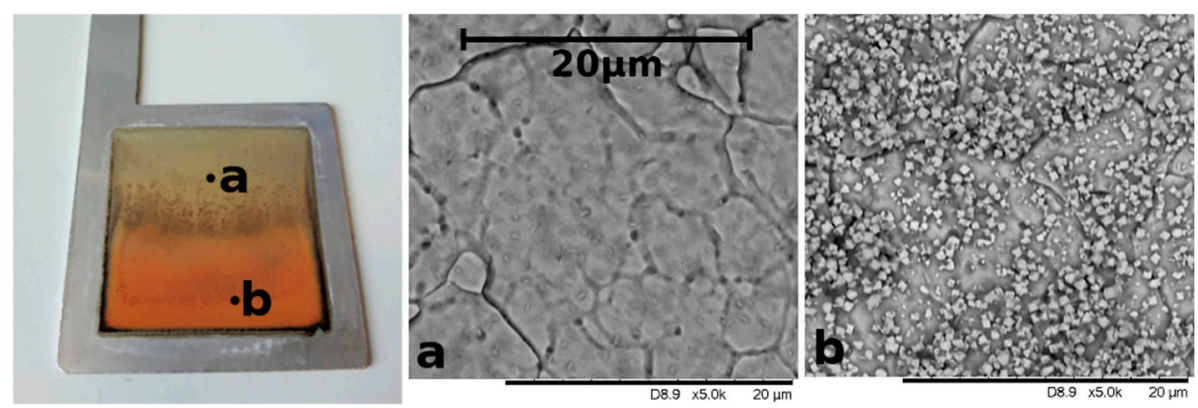

Figure 9. Electron micrographs at 5000x magnification of the stainless-steel cathode after Ageing Protocol B.

This is in agreement with the coppery colour exhibited by the electrode, but is nevertheless a surprising result, as no explicit source of copper exists in the experiment. It is therefore speculated that trace levels of copper must have been present in the electrolyte, the membrane or the stainless steel. This is supported by EDX results obtained by Kao et al. [19], and by experiments on samples of 316 grade stainless steel from two separate steel suppliers, where percentages of copper between 1 and $1.6 \mathrm{wt} \%$ were observed, even though according to official standards, 316 grade stainless steel does not contain copper. Regardless of the source of the contamination, this result highlights the extent to which copper can become highly concentrated on the cathode during intermittent use. There is, however, a negligible effect on the long-term performance of the electrode. 


\subsection{XPS (X-ray Photoelectron Spectroscopy)}

The TiN coating undergoes rapid deterioration if used even briefly as an anode, as discussed in Section 3. After sweeping from 0 to $0.7 \mathrm{~V}$ at $10 \mathrm{mV} / \mathrm{s}$, the coating changed to a deep orange-brown colour, and the electrical performance was drastically reduced. Examination of the original coating using XPS before and after this alteration produced results as shown in Figure 10. It is clear that there are more components present in the XPS signal of the original TiN coating.

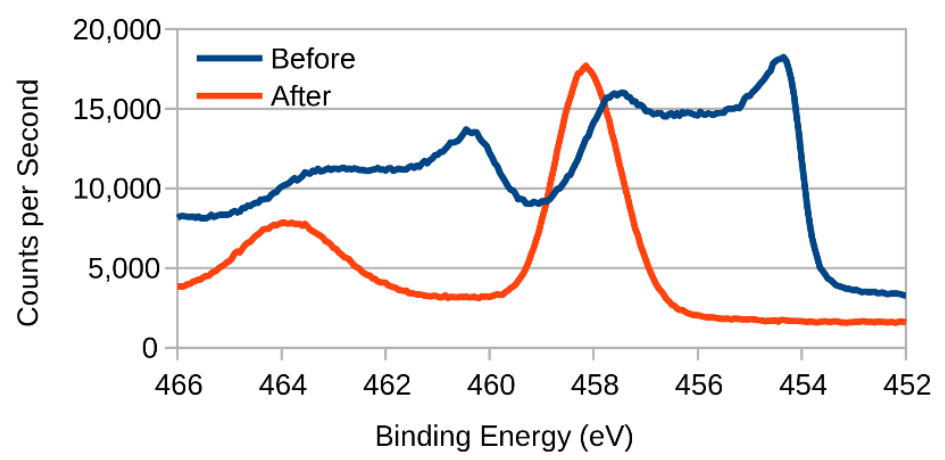

Figure 10. XPS results for the Ti $2 p$ region before and after use as an anode.

In order to identify these components, the results were analysed using CasaXPS software, which is able to perform peak fitting. Typically, all $2 p$ electron orbitals produce an XPS signal consisting of doublets, whereby the lower binding energy peak $\left(2 p_{1 / 2}\right)$ has double the area of the higher peak $\left(2 p_{3 / 2}\right)$, but the same full-width half-maximum (FWHM). However, it is known that the FWHM constraint is not entirely applicable to titanium, due to the Coster-Kronig effect, which causes a broadening of the $2 p_{1 / 2}$ peak [20]. Nevertheless, it is still possible to perform outline peak deconvolution, the results of which are as presented in Figure 11.

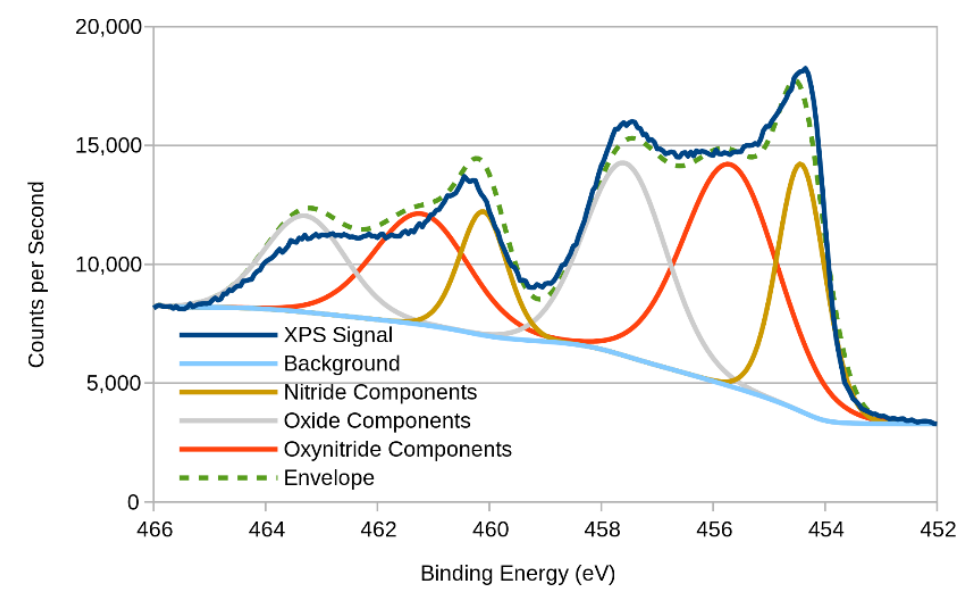

Figure 11. XPS results and component fitting for Ti $2 \mathrm{p}$ region of titanium nitride.

The fitting indicates the presence of three separate components within the overall XPS signal, which are accepted to correspond to the presence of titanium nitride and oxide [10,21], as well as oxynitride $[17,20]$, as indicated. Given the positioning of the remaining component in Figure 10 (at $\sim 458 \mathrm{eV}$ ), it is clear that after even brief use as an anode, the surface layers of the coating lost all traces of nitrogen and became oxidised titanium. This is understandable, since anodes are prone to oxidation in general, and titanium is prone to oxidation in particular [20]. A similar finding has been made by Wang et al. who observed that the higher the concentration of nitride in their oxynitride coating, the higher its tendency to be irreversibly oxidised under anodic conditions [22]. 
Since XPS is an extremely surface-sensitive analytical technique, examining exclusively the top $\sim 10 \mathrm{~nm}$, it is possible to use an ion beam to mill into the surface, and thereby obtain depth profiling information, the results of which are as shown in Figure 12. Here the numbers 1 to 9 refer to successively deeper XPS measurements and show that the nitrogen peak becomes progressively stronger with increasing depth.

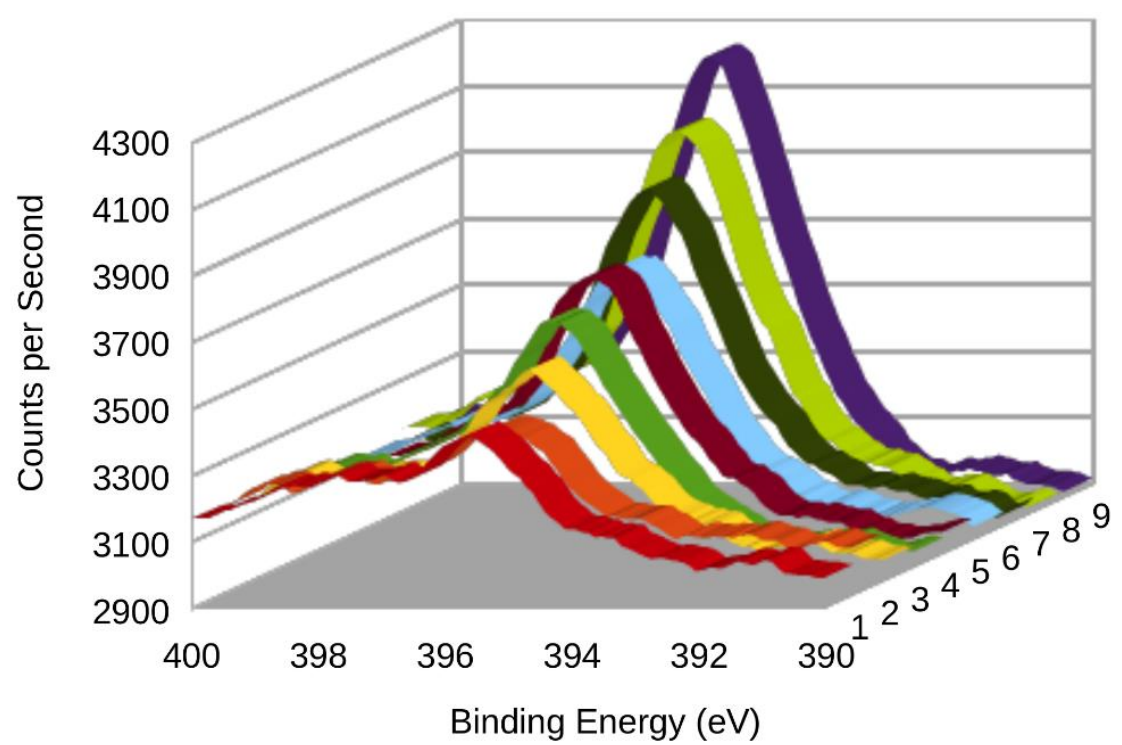

Figure 12. XPS depth profile (with smoothing) of the Ti N1s region of anodically altered titanium nitride.

The nitrogen peak reappearance indicates that the stainless steel remained protected and coated with TiN at depth, but overall the electrode incurred a loss of electrical performance caused by the oxide on the surface, which is insulating at these voltages [22]. It is therefore concluded that the phase composition of the anodically altered coating changes from $\mathrm{TiO}_{\mathrm{x}}$ at the surface, to $\mathrm{TiN}$ at depth, via a mixture including titanium oxynitride, as is confirmed by the change to an orange-brown colour [23] and the changing XPS [24-26]. The practical significance of this is that incorrect wiring or fluctuations in the polarity of the electrical input would fast render the electrolysis equipment ineffective. Therefore, in practice some sort of protection would need to be provided against reverse polarity, for example via the use of a diode and fuse, or alternatively a field-effect transistor (FET). Both solutions, however, would incur some liability, either in terms of cost or reliability.

\section{Conclusions}

The improvement to the electrical performance and reliability of 316 grade stainless steel as a cathode for water splitting by the application of a commercially available titanium nitride coating has been investigated. Initially this appears to incur a $300 \mathrm{mV}$ increase in overpotential, but over long-term intermittent experiments at $200 \mathrm{~mA} \mathrm{~cm}^{-2}$, a two-electrode cell incorporating the coating was observed to outperform the uncoated material by $250 \mathrm{mV}$. At this current density, both stainless-steel and TiN cathodes experienced significant discolouration (cf. Figure 7). This appears to be partially reversible, since the deposit is observed to dissolve into the electrolyte over several days. More importantly, the coated material demonstrated a significant increase in electrical performance after such intermittent usage, improving by $400 \mathrm{mV}$, which was enough to surpass the uncoated material. Figure 6 shows that the coated material has outperformed the uncoated material in a three-electrode system, and Figure 5 shows that it has also outperformed the coated material when employed as a complete system. The SEM results in Figures 8 and 9 show that the 'black appearance' of both cathodes actually has different underlying causes. 
Characterisation using SEM (scanning electron microscopy) confirmed that the migration and deposition of copper might be responsible for some of this increase. Electron micrographs of the coated material after ageing reveal a large number of sharply pointed copper crystals. It is theorised that these grew from a layer of copper that was deposited by the coating supplier before the titanium nitride coating was applied. For the uncoated material, many copper particles approximately $500 \mathrm{~nm}$ in diameter were observed to have been deposited. Whilst the source of this copper contamination remains unknown, their appearance is not associated with a decrease in performance.

It was also confirmed that TiN cannot be used as an anode at all, and characterisation using XPS (X-ray photoelectron spectroscopy) revealed that the coating experiences a rapid conversion to $\mathrm{TiO}_{\mathrm{x}}$, with the loss of all nitrogen from the surface layers. Ion beam milling revealed that the transition from $\mathrm{TiO}_{x}$ at the surface to $\mathrm{TiN}$ at depth is gradual, and therefore will necessarily encompass intermediary compositions of titanium oxynitride. It is possible that a ternary compound of TiAlN or CrAlN might demonstrate greater resistance to electro-oxidation, as confirmed for thermal oxidation by Chim et al. [27]. Nevertheless, this does little to detract from the applicability of TiN as a cathode for electrolytic water-splitting under intermittent room-temperature alkaline conditions.

Author Contributions: Conceptualization, C.W.D.; methodology, C.W.D.; software, W.J.F.G.; validation, W.J.F.G.; formal analysis, W.J.F.G.; investigation, W.J.F.G. and D.R.J.; resources, C.W.D.; data curation, C.W.D.; writing—original draft preparation, W.J.F.G.; writing—review and editing, W.J.F.G.; visualization, W.J.F.G.; supervision, W.J.F.G.; project administration, C.W.D.; funding acquisition, C.W.D.

Funding: PhD student William Gannon, funded by a University of Swansea Zienkiewicz Scholarship.

Acknowledgments: We would like to acknowledge the assistance provided by Swansea University College of Engineering AIM Facility, which was funded in part by the EPSRC (EP/M028267/1), the European Regional Development Fund through the Welsh Government (80708) and the Sêr Solar project via the Welsh Government. WJG thanks the Zienkiewicz Centre for his PhD funding.

Conflicts of Interest: The authors declare no conflict of interest.

\section{References}

1. Mazloomi, K.; Gomes, C. Hydrogen as an energy carrier: Prospects and challenges. Renew. Sustain. Energy Rev. 2012, 16, 3024-3033. [CrossRef]

2. Sharma, S.; Ghoshal, S.K. Hydrogen the future transportation fuel: From production to applications. Renew. Sustain. Energy Rev. 2015, 43, 1151-1158. [CrossRef]

3. Maghami, M.R.; Asl, S.N.; Rezadad, M.E.; Ale Ebrahim, N.; Gomes, C. Qualitative and quantitative analysis of solar hydrogen generation literature from 2001 to 2014. Scientometrics 2015, 105, 759-771. [CrossRef] [PubMed]

4. Gutiérrez-Martín, F.; Confente, D.; Guerra, I. Management of variable electricity loads in wind - Hydrogen systems: The case of a Spanish wind farm. Int. J. Hydrogen Energy 2010, 35, 7329-7336. [CrossRef]

5. Phillips, R.; Dunnill, C.W. Zero gap alkaline electrolysis cell design for renewable energy storage as hydrogen gas. RSC Adv. 2016, 6, 100643-100651. [CrossRef]

6. Phillips, R.; Edwards, A.; Rome, B.; Jones, D.R.; Dunnill, C.W. Minimising the ohmic resistance of an alkaline electrolysis cell through effective cell design. Int. J. Hydrogen Energy 2017, 42, 23986-23994. [CrossRef]

7. Olivares-ramírez, J.M.; Campos-cornelio, M.L.; Godínez, J.U. Studies on the hydrogen evolution reaction on different stainless steels. Int. J. Hydrogen Energy 2007, 32, 3170-3173. [CrossRef]

8. Carta, R.; Dernini, S.; Polcaro, A.M.; Ricci, P.F.; Tola, G. The influence of sulphide environment on hydrogen evolution at a stainless steel cathode in alkaline solution. J. Electroanal. Chem. 1988, 257, 257-268. [CrossRef]

9. Schäfer, H.; Beladi-Mousavi, S.M.; Walder, L.; Wollschläger, J.; Kuschel, O.; Ichilmann, S.; Sadaf, S.; Steinhart, M.; Küpper, K.; Schneider, L. Surface Oxidation of Stainless Steel: Oxygen Evolution Electrocatalysts with High Catalytic Activity. ACS Catal. 2015, 5, 2671-2680. [CrossRef]

10. Devia, D.M.; Restrepo-Parra, E.; Arango, P.J. Comparative study of titanium carbide and nitride coatings grown by cathodic vacuum arc technique. Appl. Surf. Sci. 2011, 258, 1164-1174. [CrossRef]

11. Cho, E.A.; Jeon, U.-S.; Hong, S.-A.; Oh, I.-H.; Kang, S.-G. Performance of a 1kW-class PEMFC stack using TiN-coated 316 stainless steel bipolar plates. J. Power Sources 2005, 142, 177-183. [CrossRef] 
12. WallworkHT Commercial Coatings (PVD). Available online: https://www.wallworkht.co.uk/content/ commercial_coatings / (accessed on 28 January 2019).

13. Pletcher, D.; Li, X. Prospects for alkaline zero gap water electrolysers for hydrogen production. Int. J. Hydrogen Energy 2011, 36, 15089-15104. [CrossRef]

14. Passas, G.; Dunnill, C.W. Water Splitting Test Cell for Renewable Energy Storage as Hydrogen Gas. Fundam. Renew. Energy Appl. 2015, 5, 3-8.

15. Stevens, M.B.; Enman, L.J.; Batchellor, A.S.; Cosby, M.R.; Vise, A.E.; Trang, C.D.M.; Boettcher, S.W. Measurement Techniques for the Study of Thin Film Heterogeneous Water Oxidation Electrocatalysts. Chem. Mater. 2016, 29, 120-140. [CrossRef]

16. Milosev, I.; Strehblow, H.-H.; Navinsek, B. Comparison of TiN, ZrN, and CrN coatings under oxidation.pdf. Thin Solid Films 1997, 303, 246-254. [CrossRef]

17. Gebauer, C.; Fischer, P.; Wassner, M.; Diemant, T.; Jusys, Z.; Hüsing, N.; Behm, R.J. Performance of titanium oxynitrides in the electrocatalytic oxygen evolution reaction. Nano Energy 2016, 29, 136-148. [CrossRef]

18. Shinagawa, T.; Garcia-esparza, A.T.; Takanabe, K. Insight on Tafel slopes from a microkinetic analysis of aqueous electrocatalysis for energy conversion. Sci. Rep. 2015, 5, 13801. [CrossRef] [PubMed]

19. Kao, C.T.; Ding, S.J.; Chen, Y.C.; Huang, T.H. The anticorrosion ability of titanium nitride (TiN) plating on an orthodontic metal bracket and its biocompatibility. J. Biomed. Mater. Res. 2002, 63, 786-792. [CrossRef] [PubMed]

20. XPS Interpretation of Titanium. Available online: https://xpssimplified.com/elements/titanium.php (accessed on 7 June 2018).

21. Shimada, S.; Hasegawa, M. Preparation of Titanium Nitride Films from Amide Precursors Synthesized by Electrolysis. Society 2003, 79, 177-179.

22. Wang, W.; Savadogo, O.; Ma, Z.F. Preparation of new titanium oxy nitride based electro catalysts using an anhydrous sol-gel method for water electrolysis in acid medium. Int. J. Hydrogen Energy 2012, 37, 7405-7417. [CrossRef]

23. Chappé, J.M.; Martin, N.; Lintymer, J.; Sthal, F.; Terwagne, G.; Takadoum, J. Titanium oxynitride thin films sputter deposited by the reactive gas pulsing process. Appl. Surf. Sci. 2007, 253, 5312-5316. [CrossRef]

24. Dunnill, C.W.; Aiken, Z.A.; Pratten, J.; Wilson, M.; Parkin, I.P. Sulfur-and nitrogen-doped titania biomaterials via APCVD. Chem. Vap. Depos. 2010, 16, 50-54. [CrossRef]

25. Dunnill, C.W.; Ansari, Z.; Kafizas, A.; Perni, S.; Morgan, D.J.; Wilson, M.; Parkin, I.P. Visible light photocatalysts- $\mathrm{N}$-doped $\mathrm{TiO}_{2}$ by sol-gel, enhanced with surface bound silver nanoparticle islands. J. Mater. Chem. A 2011, 21, 11854-11861. [CrossRef]

26. Dunnill, C.W.; Parkin, I.P. N-Doped Titania Thin Films Prepared by Atmospheric Pressure CVD using t -Butylamine as the Nitrogen Source: Enhanced Photocatalytic Activity under Visible Light. Chem. Vap. Depos. 2009, 15, 171-174. [CrossRef]

27. Chim, Y.C.; Ding, X.Z.; Zeng, X.T.; Zhang, S. Oxidation resistance of TiN, CrN, TiAlN and CrAlN coatings deposited by lateral rotating cathode arc. Thin Solid Films 2009, 517, 4845-4849. [CrossRef] 